\title{
Métodos de gestão ambiental das empresas do agronegócio do Município de Baixa Grande do Ribeiro, Estado do Piauí, Nordeste do Brasil: implicações e desafios
}

\section{Gilberto Soares da Silva*, Warton Silva Souza}

Universidade Federal do Tocantins. Campus Universitário de Araguaína. Avenida Paraguai. Bairro da Cimba. Araguaína-TO, Brasil (CEP 77824-838). *E-mail: gilbertosoares@mail.uft.edu.br.

Resumo. 0 desenvolvimento sustentável tem recebido grande ênfase no cenário internacional, devido à repercussão dos problemas ambientais. As empresas estrategicamente se enquadram na política de crescimento equilibrado, delineando novas ações em seus ambientes internos. Como o agronegócio é parte fundamental na economia do Município de Baixa Grande do Ribeiro, no Estado do Piauí, Nordeste do Brasil, questionamentos surgiram para analisar se o crescimento econômico regional está alinhado à sustentabilidade. Portanto, este trabalho teve por finalidade compreender a postura das empresas do agronegócio do município citado, frente à política de desenvolvimento equilibrado entre econômico, social e ambiental. Para se chegar ao resultado foi desenvolvida uma pesquisa de cunho quanti-qualitativo, através de um estudo de caso junto aos setores estratégicos dessas fazendas, por meio dos representantes administrativos. 10 empresas participaram das entrevistas, que contava com um questionário semiestruturado, de perguntas fechadas e, às vezes, abertas, tencionadas a compreender, quais práticas são implementadas por elas e quais desafios são encontrados nesse processo. Como principais resultados, percebeu-se que essas organizações são esclarecidas sobre a importância de trabalhar com ferramentas e práticas sustentáveis, principalmente, pela viabilidade de atingir as metas da empresa alinhadas à sustentabilidade. Contudo, nota-se que muito ainda deve ser trilhado para efetivar ações que consolidem uma política de adequação ao desenvolvimento sustentável.

Palavras-chave: Gestão ambiental; Sustentabilidade; Agronegócio; Crescimento sustentável.

Abstract. Methods of environmental management of the agribusiness companies of Baixa Grande do Ribeiro, State of Piauí, Northeast Brazil: Implications and challenges. Sustainable development has received great emphasis on the international scene, due to the repercussion of environmental problems. Companies strategically fit into the policy of balanced
Recebido:

26/04/2018

Aceito:

$17 / 07 / 2018$

Publicado:

$31 / 08 / 2018$

Acesso aberto

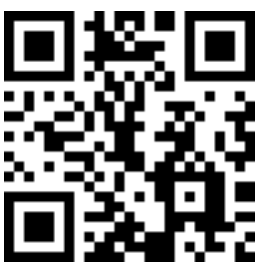

ORCID

(D) 0000-0003-4595-9031

Gilberto Soares da

Silva

(D) 0000-0002-5337-014X

Warton Silva Souza 
growth, outlining new actions in their internal environments. As agribusiness is a fundamental part of the economy of Baixa Grande do Ribeiro, Piauí State, Northeast Brazil, questions have arisen to analyze whether regional economic growth is aligned with sustainability. Therefore, this work aimed to understand the posture of the agribusiness companies of the mentioned municipality, before the policy of balanced development between economic, social and environmental. In order to arrive at the result, a quantitative-qualitative research was developed, through a case study with the strategic sectors of these farms, through the administrative representatives. Ten companies participated in the interviews, which had a semi-structured questionnaire, closed and sometimes open questions, intended to understand which practices are implemented by them, and which challenges are encountered in this process. As main results, these organizations were clarified about the importance of working with sustainable tools and practices, mainly for the feasibility of achieving the company's goals aligned with sustainability. However, it should be noted that much still needs to be done to implement actions that consolidate a policy of adaptation to sustainable development.

Keywords: Environmental Management; Sustainability; Agribusiness; Sustainable growth.

\section{Introdução}

A sociedade atual tem passado por grandes modificações referentes aos valores ambientais, que evoluíram de um simples interesse ao topo da problemática. Essa evolução se deve à percepção de que sobrevivência dos seres humanos se encontra ameaçada por conta da escassez e degradação dos recursos naturais, a extinção de espécies da fauna e flora, o aumento do volume oceânico, o crescente aquecimento da temperatura causado pela emissão de gases derivados da queima de combustíveis fósseis. Assim, todos estes aspectos relacionados à questão ambiental tornaram-se destaque nos debates internacionais. Desse modo, levando em conta as questões ambientais de modo geral, verifica-se que este tema vem ganhando espaço nas empresas. De forma mais específica, essas empresas compreendem que, além da conscientização carecem de combinar uma política interna visando a integrar econômico, social e ambiental (Boof, 2007; Sachs, 2007).

Percebe-se que, a preocupação com o meio ambiente passou a ser debatida com maior profundidade nas últimas décadas do século XX (Jabbour e Santos, 2006). Nesta perspectiva, algumas empresas no Brasil ainda consideram os problemas ambientais em segundo plano. Mas, a partir da década de 80 , as organizações passaram a sofrer pressões por regulamentações do Governo, e pela própria sociedade, consequentemente, promovendo mudanças no ambiente empresarial (Seiffert, 2007). Pensando no potencial econômico que as empresas possuem, levantou-se o seguinte questionamento para nortear esta proposta de pesquisa: quais medidas são adotadas pelas empresas do agronegócio para viabilizar seu crescimento e solucionar problemas relacionados ao meio ambiente e bemestar social?

Este artigo analisa a relevância das ações ambientais sustentáveis 
implementadas pelas empresas do agronegócio, no Município de Baixa Grande do Ribeiro, Estado do Piauí, como sinônimo de desenvolvimento econômico sustentável. Para melhor especificar a abordagem, procurou-se visualizar as seguintes vertentes: a) analisar os princípios e objetivos da gestão ambiental adotados pelas empresas do agronegócio (soja); b) identificar a existência ou não de um modelo de gestão de empresas ambientalmente corretas nas empresas pesquisadas; c) identificar as ações e desafios sustentáveis adquiridas por empresas que lutam pela causa ambiental em seu modelo de crescimento econômico; d) analisar o uso e implicações de uma política ambiental em suas ações administrativas; e, e) estabelecer uma comparação conceitual com os modelos adotados pelas empresas.

0 trabalho se justifica em função do cumprimento das normas em vigor e, também pela urgência e importância que a gestão ambiental tem despertado na sociedade em geral. Principalmente, pela percepção de que as crises ambientais não têm caráter passageiro, mas por ser uma questão prioritária para o sustento da humanidade (Porter e Kramer, 2006; Barbieri, 2007). Ressalta-se ainda, a importância que a gestão administrativa tem nesse contexto, através de interações sustentáveis em articulação com as organizações governamentais e sociedade, por estratégias de sobrevivência (Porter e Kramer, 2006).

Percebe-se que a gestão ambiental tem recebido ênfase diante do comportamento da sociedade. Portanto, mediante o reconhecimento no contexto empresarial, muitas empresas têm adotado o "selo verde" como forma de assegurar uma imagem positiva perante os consumidores e até mesmo fornecedores. Isso se deu em virtude de cobranças por ações e políticas voltadas a preservação dos recursos ambientais, principalmente, mediante as consequências de indevidos e os grandes desafios de superação que implicam na sustentabilidade (Bateman e Sneel, 1998).

Este reconhecimento por parte das empresas, em garantir práticas de gestão ambiental, são frutos de pressões do ambiente externo, e também, estratégias de sobrevivência econômica e qualidade de vida social. Os resultados econômicos devem estar munidos de técnicas inovadoras, paralelas às corretas práticas ambientais e socialmente justas. Contudo, o empresariado ainda não está voltado para essas mudanças, mesmo com a regulamentação de normas e programas de conscientização. Ainda há muito a ser feito, mesmo naquelas que já possuem práticas que buscam o sustento ambiental. Daí, o grande desafio é manter, estimular, motivar e treinar os recursos disponíveis, assegurando o equilíbrio ambiental ao atingir as metas da organização (Andrade et al., 2000).

Ainda neste contexto, Almeida (2002, p. 33) ratifica que a questão ecológica desafia a estrutura das organizações, "a sustentabilidade exige uma postura preventiva, que identifique tudo que um empreendimento pode causar de positivo - para ser maximizado - e de negativo - para ser minimizado". Não se deve entender o crescimento sustentável como um empecilho para o desenvolvimento econômico, mas como uma força aliada no processo de crescimento, uma vez que a sociedade tem buscado ações nesse sentido por parte das empresas.

\section{Fundamentação teórica}

Nos últimos anos, questões relacionadas ao meio ambiente ganharam destaque internacional, resultado de discussões que analisavam a sustentabilidade ambiental, levando sociedade e organizações a adotarem novas posturas em relação ao contexto econômico, social e ambiental.

A preocupação com o esgotamento dos recursos naturais ganhou impulso anos depois da Revolução Industrial, devido à 
capacidade humana de promover alterações ambientais. Com isso, após ser comprovada a interdependência entre Economia e Meio Ambiente, essa nova percepção cresceu de forma surpreendente, alterando a preocupação ambiental nos processos produtivista. Assim, gestão ambiental é essencial para efetivar as práticas de sustentabilidade (Donaire, 1999; Barbieri, 2004; Veiga, 2010).

No contexto social o tema data, aproximadamente, de meados do século $\mathrm{XX}$, quando houve a conscientização acerca de uma série de problemas surgidos pelo desenvolvimento das populações: poluições, limitações dos recursos naturais, deteriorações de áreas ambientais etc. $O$ que se observou nos anos subsequentes foi essa identificação da problemática pela sociedade, tendo como destaque eventos, relatórios e documentos que buscavam compreender essa relação entre o homem e o meio ambiente, propondo posturas de desenvolvimento equilibrado (Leff, 2001).

Cientificamente, as ideias ambientais provem do esforço de assegurar o equilíbrio do meio natural, na identificação e estudo de seus componentes, assim analisar os problemas, suas causas e consequências. Porém, essas questões que tomaram essa dimensão na atualidade já haviam sido pensadas ao longo do tempo. Nesse contexto, Ferreira (2010) discute que desde1824, J Fourier já se interrogava sobre o estabelecimento e o progresso das sociedades humanas, as forças da natureza e seus efeitos respectivamente a nível planetário. Já as forças higienistas, no século XVIII, levantaram questões ligadas ao hábitat e a qualidade de vida. Assim, no século XIX, as corporações encarregadas da gestão dos recursos naturais já se questionavam sobre o seu possível esgotamento.

Foram questões como essas que nos dias atuais ganharam grande importância, pois o alargamento, a universalização dos problemas e a tomada de consciência a respeito dessa interdependência se tornaram visíveis de forma acentuada.

A partir de 1950, "a relação entre a questão ambiental e o desenvolvimento econômico passou a ser analisada como consequência de uma reavaliação dos resultados do crescimento econômico" (Donaire, 1999, p. 16). Esse movimento deve-se à constatação de que a economia não pode ser vista como um sistema à parte, desvinculado do uso dos recursos naturais, comprovados pela necessidade humana pela água, fotossíntese ou ações com o solo. Cavalcanti (1998) ressalta que quando as organizações extrapolam os limites da natureza e suas possibilidades de produção, torna-se insustentável. Pois, manter o desenvolvimento sustentável requer a construção de conceitos e métodos, considerando as restrições ambientais desse crescimento.

Para Espinosa (1993), a crescente expansão das capacidades de produção, aliadas ao acelerado crescimento da população colocou em evidência o esgotamento dos recursos naturais na produção de serviços, constituindo uma grave ameaça ao bem-estar presente e ao futuro da sociedade. Dessa forma, essas questões conquistaram maior destaque nos debates entre as nações. Por meio de reuniões e acordos foram reiteradas e ratificadas, na adoção de medidas concretas na defesa do meio ambiente, especialmente, quando o assunto é econômico. Assim, ao evidenciar que medidas de proteção ambiental não são entraves para o desenvolvimento econômico, instituições e empresas reorganizam e/ou adotam ações considerando o fator custo/beneficio na implantação de seus projetos econômicos.

Ainda nessa perspectiva, Tachizawa (2007), menciona que essas alterações voltadas para o desenvolvimento sustentável se fizeram sentir de modo acentuado no modo como as empresas interagem com seu público. Aponta também que, ao delinear 
estratégias ambientalmente corretas, destacam-se competitivamente, além de, às vezes reduzir custos e potencializar lucros no médio e longo prazo.

Portanto, compreende-se que as empresas que alinham seu crescimento às questões ambientais, promovem investimentos em sua força competitiva. Para Dias (2014), a sociedade contemporânea está preocupada com as questões ambientais, valorizando também, aspectos como distribuição de renda, qualidade de vida, relacionamento humano e realização pessoal. Além disso, a atenção que a sociedade revelou no comportamento ético das empresas, teve como resultado a reformulação de leis e regras que versam sobre o padrão ético das corporações. Isso fez com que despertasse novas posturas estratégicas em face das mudanças provocadas nas regras de atuação no mercado.

\section{Contexto da gestão ambiental nos negócios}

O tema ambiental fez um novo conceito surgir no mundo empresarial, o desenvolvimento sustentável "que atende às necessidades do presente sem comprometer as possibilidades das gerações futuras atenderem as suas próprias", conceito da Comissão Mundial sobre o Meio Ambiente e Desenvolvimento, apresentado em 1987 (CMMAD, 1991, p. 46). Sobre esse conceito não há consenso entre os estudiosos, ressalta-se que mediante os vários debates, cada pesquisador deve delinear, através das dimensões da sustentabilidade, conforme o objeto que será pesquisado, as especificidades que melhor atendam à pesquisa (Veiga, 2010).

Ainda nesse aspecto, Bell e Morse (2008) e Dias (2014) apontam o desenvolvimento sustentável benefício empresarial, somados ao crescimento econômico, oferta de serviços e manutenção da qualidade dos recursos naturais. Isso gera a conservação dos recursos, alterando inclusive, 0 comportamento humano na sua interrelação com a natureza. Para Sachs (2002) a finalidade do desenvolvimento sustentável consiste na sustentação da riqueza internacional, em seu entendimento, deve-se observar o sustento dos sistemas financeiros, recursos naturais e a qualidade de vida social.

Dias (2014) analisa que a temática ambiental na gestão das empresas é espectro natural do desenvolvimento do pensamento humano em relação à utilização dos recursos naturais de forma coerente. Nada mais é, do que a autorregulação dos empreendedores na busca de iniciativas responsáveis que permitam sustentar o meio ambiente. Esse novo conceito surgiu mediante fortes pressões advindas do próprio mercado, agentes públicos, bancos, consumidores, fornecedores, exigindo das empresas de todo o mundo, na busca de soluções, através de medidas de crescimento, observando as legislações ambientais que foram elaboradas a partir dessas discussões.

Conforme esse contexto foi sendo inserido nas empresas, as questões ambientais estavam sendo apreciadas como um "conjunto de decisões exercidas sob princípios de qualidade ambiental e ecológica preestabelecidos, com a finalidade de atingir e preservar um equilíbrio dinâmico entre objetivos, meios e atividades no âmbito da organização" (Andrade et al., 2000, p. 92).

As ideias provem de eco desenvolvimento, proposto nos anos 1970, durante a 1a Conferência das Nações Unidas sobre o Meio Ambiente e Desenvolvimento em Estocolmo, 1972. Originou-se a partir daí o Programa das Nações Unidas para o Meio Ambiente (PNUMA). Foi a partir de então, que a temática ambiental passou a ser discutida na relação entre os países, principalmente por apresentar benefícios na relação entre a natureza e aspectos socioeconômicos (Sachs, 2002). Para o 
autor o conceito de ecodesenvolvimento ou desenvolvimento sustentável, pode ser evidenciado numa proposta que designa oito vertentes essenciais de sustentabilidade: social, cultural, ecológica, ambiental, territorial, econômica, política nacional e política internacional.

No caso do Brasil, outro evento importante a nível global, refere-se à conferência sobre Meio Ambiente e Desenvolvimento realizada no Rio de Janeiro, em junho de 1992, teve como resultado a elaboração da Agenda 21, com a finalidade de discutir mecanismos viáveis para dirimir a degradação ambiental. Em conjunto com a Carta da Terra ou Declaração do Rio, esses programas concentram-se nas mais diferentes áreas: "atmosfera, recursos da terra, agricultura sustentável, florestas, biotecnologia, mudanças climáticas, oceanos, meio ambiente marinho, água potável, resíduos sólidos, resíduos tóxicos, rejeitos perigosos", entre outros (Silva, 2003, p. 12).

Copobianco (1990, p. 3) afirma que o modelo de crescimento adotado no país, que pretende desenvolver a indústria de modo acelerado, gerou "deseconomias" de escala. Estas estavam impressas nos problemas de urbanização, perceptíveis nos grandes níveis de poluição provocados pelas indústrias, saneamento urbano precário e nas redes de abastecimento de água que afetam grandes cidades do país.

Vários países assumiram a responsabilidade de promover políticas de crescimento, promovendo o equilíbrio entre o ambiental, social e econômico. Para Kraemer (2004), isso se deve à sensibilização sobre o ambiente natural, foco das discussões que aconteceram em todo o mundo desde 1970, novas reuniões são realizadas no intuito de avaliar os avanços ocorridos após a assinatura dos acordos pelas nações do mundo, como é o caso, da Cimeira de Johanesburgo, em 2002 e da Rio+20, em 2012.

\section{Gestão ambiental: a nova ótica organizacional}

0 termo Gestão Ambiental consiste numa "tentativa de avaliar valores e limites das perturbações e alterações que, uma vez excedidos, resultam em recuperação dos recursos do ecossistema natural para o homem, assegurando sua produtividade prolongada e de longo prazo" (Ferreira, 2010, p. 39).

Donaire (1999, p. 16) afirma que uma quantidade crescente de atenção, por parte das organizações, volta-se para preocupações de "caráter político-social, tais como proteção ao consumidor, controle da poluição, segurança e qualidade de produção, assistência médicas e sociais e defesas de grupos minoritários". Ocorreu uma proliferação de novas pressões por parte da sociedade que resultam em novas leis e regulamentações que alteram as regras do jogo. Assim, essas mudanças afetam de forma intensa o ambiente social e político em que a empresa atua.

0 conceito de desenvolvimento sustentável passa a ser analisado a partir de três pontos fundamentais no ambiente das empresas: a) crescimento econômico; b) equidade social; e c) equilíbrio ecológico (Donaire, 1994). Assim, buscar-se-á a racionalização dos recursos da natureza, beneficiando o crescimento equitativo da sociedade e o equilíbrio das fontes naturais. Conforme Quezada e Pierre (1998, p. 51), a gestão ambiental empresarial, volta-se para as empresas e instituições, sendo definida como um sistema de ações administrativas e operacionais que observam a saúde segurança dos recursos humanos, bem como, a proteção do meio ambiente, por meio da mitigação dos impactos e danos ambientais. Com isso, as organizações buscam dirimir os impactos nas fases de planejamento, implantação, realização, alargamento, 
realocação, fechamento de empreendimentos e atividades, em observação a todas as etapas da série de vida do produto.

Essa nova preocupação nas organizações, fez com que a ótica voltada para a gestão ambiental desenvolvesse uma política empresarial fundamentadas em diretrizes e ações. Como resultado alguns objetivos devem ser alcançados, tais como: promoção na gestão de políticas, diretrizes e programas relacionados ao ambiente interno e externo; manutenção do bem-estar social dos colaboradores, mantendo a saúde e segurança de todos; produção de serviços e produtos ambientalmente corretos; e, realização de contribuições econômicas, sociais e ambientais nas metas e objetivos da instituição (Ferreira, 2010).

Considerando o contexto organizacional, $\mathrm{o}$ inovador modelo de gestão tem uma grande importância, inclusive estratégica, de modo que, essa referência ambiental adotada pela administração, leva a empresa a ter potencial competitivo. Neste sentido, as empresas carecem se atentar aos mecanismos de execução de atividades inovadoras para se chegar a excelência ambiental. A Tabela 1 apresenta algumas medidas que podem ser observadas pelas empresas que pretendem se adequar às políticas ambientais e socioeconômicas.

Tabela 1. Princípios de gestão ambiental.

\begin{tabular}{|c|}
\hline Passos para a excelência ambiental \\
\hline Estabeleça e publique uma política ambiental; \\
\hline Desenvolva metas e continue a avaliar os ganhos; \\
\hline $\begin{array}{l}\text { 3. Defina claramente as responsabilidades ambientais de cada uma das áreas e do } \\
\text { pessoal administrativo (Linha ou Acessoria): }\end{array}$ \\
\hline $\begin{array}{l}\text { 4. Divulgue interna e externamente a política, os objetivos e metas e as } \\
\text { responsabilidades; }\end{array}$ \\
\hline 5. $\quad$ Obtenha os recursos adequados; \\
\hline Eduque e treine seu pessoal e informe os consumidores e comunidade; \\
\hline Acompanhe a situação ambiental da empresa e faça auditoria e relatórios; \\
\hline Acompanhe a evolução da discussão ambiental; \\
\hline $\begin{array}{l}\text { 9. Contribua para os programas ambientais da comunidade e invista em pesquisa e } \\
\text { desenvolvimento aplicado à área ambiental; }\end{array}$ \\
\hline $\begin{array}{l}\text { 10. Ajude a atuar junto aos diferentes interesses existentes entre todos os } \\
\text { envolvidos: empresa, consumidores, comunidade, acionistas. }\end{array}$ \\
\hline
\end{tabular}

Fonte: Modificado de Elkington e Burke (1989).

As empresas necessitam ficar atentas a cada mudança que o mercado apresenta, pois não se trata de escolhas, mas sim uma necessidade de sobrevivência. Manter uma política ambiental, e acima de tudo expor e motivar os colaboradores na busca desse objetivo comum, visando ao desenvolvimento econômico e proteção ambiental, e não um conflito, visto que o mesmo reforça o sustento do presente e também de gerações futuras (Barbieri, 2007).

Para Elkigton e Burke (1989) seguir os passos para obter a excelência ambiental é uma forma estratégica para ganhar espaço no mercado, através da gestão da qualidade que visa ao bemestar da organização e da sociedade. A empresa agora assume um papel ativo e inovador frente às políticas ambientais e sociais. 
Portanto, a partir desses objetivos, as organizações assumem a missão de reunir instrumentos necessários à mitigação dos impactos contra o ambiente. Dessa maneira, dada a importância adquirida pela gestão e preservação ambiental rumo ao desenvolvimento sustentável, torna-se imprescindível que os 16 princípios essenciais da administração ambiental, sejam devidamente observados conforme consta na carta empresarial. Estes devem: a) priorizar a gestão ambiental; b) promover a gestão integrada de políticas de ação; c) desenvolver técnicas de melhoria contínua; d) capacitar e treinar o quadro de pessoal; e) realizar avaliação prévia com análises de impactos; f) inovar na oferta de produtos e serviços; g) trabalhar na conscientização do consumidor; h) investir em instalações de equipamentos e operacionalização; i) fomentar a realização de pesquisas; j) desenvolver mecanismo com foco no preventivo; k) buscar por fornecedores e subcontratados que atendam as políticas internas l) controle e planos de emergência de impactos; $\mathrm{m}$ ) mudança para tecnologias de menor impacto; n) reforço ao esforço comum na criação de políticas e parcerias para a sustentabilidade; o) promover um diálogo com o público sobre as preocupações ambientais; e p) realizar avaliações do desempenho organizacional (Andrade et al., 2000).

Em suma, notou-se que as organizações devem buscar a criação de princípios que reestruturem suas ações enquanto produtora ou prestadora de serviços, promovendo a melhoria contínua de medidas socioambientais. Essa postura de adequação deve ser realizada nos mais diferentes ambientes e ramos empresariais, pois, tornou-se para fundamental que todos os empreendimentos se configurem em atenção aos impactos ambientais que causam. No caso em tela, buscaremos analisar as organizações que lidam com o agronegócio no sul do estado piauiense.
Assim, a seguir, apresentam-se os aspectos metodológicos utilizados nesta pesquisa para a obtenção e análise dos dados.

\section{Metodologia}

Em face da busca pelo método mais apropriado para se chegar aos resultados pretendidos, segundo Yin (2010), o estudo de caso favorece através de investigações empíricas a compreensão de dados, por meio de um método abrangente. Para isso, busca-se fazer planos de trabalho, coleta e avaliação dos dados. Desse modo, podese ainda fazer o estudo de casos voltados para um único objeto, como também, casos múltiplos.

Nesse sentido, analisamos o caso do munícipio de Baixa Grande do Ribeiro no Piauí, em virtude de seu potencial na área do agronegócio. Estuda-se o caso de empresas que atuam no ramo, observando as percepções dos gestores quanto aos desafios e perspectivas na adoção de políticas internas de gestão ambiental.

A natureza da pesquisa é teórica e possui caráter descritivo baseando-se em estudos que contribuam para o avanço desta área de conhecimento, perfazendo esboços que abordem o tema da gestão ambiental no âmbito das organizações que pretendam ser sustentáveis (Cervo, Bervian e Silva, 2007; Gil, 2010). Portanto, de acordo com o estudo de caso, o investigador possui ferramentas importantes na identificação de fronteiras, proporcionando a concepção aprofundada dos casos ou uma parametrização de vários casos (Yin, 2010).

A abordagem desta pesquisa tem cunho quanti-qualitativo. Conforme Neves (1996), a soma dessas duas abordagens fornece $o$ entendimento aprofundando dos objetivos que se pretendem alcançar. Para o autor, a pesquisa qualitativa fornece particularidades que considera o objeto como fonte primária dos dados e o 
pesquisador como ferramenta chave. Já a pesquisa quantitativa enumera valores e estatísticas com relação às informações, nos indicando fenômenos reais e a procura por valores ideais.

A técnica utilizada para a coleta dos dados foi por meio de entrevistas realizadas com 10 gestores de fazendas agropecuárias do munícipio supracitado, discorrendo sobre rotinas e ações que promovem políticas de gestão ambiental. Essa entrevista foi promovida por um questionário de 32 questões, com perguntas fechadas, abertas e múltipla escolha, que viabilizaram analisar a visão, práticas, desafios e consequências das atividades ambientais nas empresas pesquisadas.

A entrevista como técnica de coleta de dados tem como vantagem a oportunidade de o avaliador conseguir visualizar atitudes, condutas, através da observação nas falas do entrevistado (Gil, 2010). Outro ponto positivo é a descoberta de dados que não se encontram em documentos, mas, que são relevantes e significativos, assim como, a possibilidade de quantificar e conseguir informações mais precisas. E, embora apresente algumas limitações e desvantagens, o pesquisador pode sanálas ou minimizá-las (Lakatos e Marconi, 2010). Ainda com relação a essa técnica, Bogdan e Bickeln (1994), a entrevista pode ser utilizada como método único ou auxiliar para a coleta de dados em uma pesquisa.

Os dados são analisados considerando a proporção das respostas dos gestores entrevistados, validados pelas observações documentais. Ressalta-se também, a comparação com as bibliografias pesquisadas para fundamentar este estudo. Dessa forma, a seção seguinte busca descrever o objeto deste estudo, seguida da discussão dos principais resultados da pesquisa.

\section{Resultados e discussão}

Atualmente, percebeu-se que a questão ambiental influencia na forma como as empresas organizam seus métodos de gestão e sua posição na busca pelo crescimento econômico e sustentável. Neste sentido, as organizações, independente do ramo em que atuam, inclusive as do agronegócio, devem se preocupar com a problemática de modo geral, focando em ações antes, durante e depois do processo produtivo. Faz-se necessário buscar meios que tornem possíveis o desenvolvimento da produção, somados a mecanismos que atendam aspectos sociais, ambientais e culturais, bom como a destinação dos produtos e serviços.

O desenvolvimento sustentável não é um movimento unicamente dos ecologistas e ambientalistas, mas uma nova postura assumida nas atitudes empresariais que representam o ganho financeiro de longo prazo e melhoria continua no ambiente das empresas. A gestão de sistemas ambientais e socialmente corretos, além da viabilidade econômica é integrada nas empresas do agronegócio como respostas às pressões da sociedade por modelos de produção sustentáveis.

A preocupação nasce na percepção que os recursos disponíveis sofrem um ritmo desregrado de esgotamento. Frente a essa questão, as empresas do agronegócio de Baixa Grande do Ribeiro mostraram na elaboração teórica de suas missões que buscam gerenciar valores, desenvolver técnicas inovadoras e modernas para a oferta de produtos de qualidade, observou-se também que a realização dessa tarefa está associada à sustentabilidade dos recursos naturais e geração de melhorias sociais.

O Município de Baixa Grande do Ribeiro, localizado no sul do Estado do Piauí, a $583 \mathrm{~km}$ de Teresina, é o segundo maior município do estado em extensão territorial, com $7.809 \mathrm{~km}^{2}$. É hoje forte alvo de localização de fazendas agropecuárias, juntamente com outros municípios, formam um polo de produção agrícola no sul do estado. Os dados agrícolas municipais segundo os 
dados do censo do Instituto Brasileiro de Geografia e Estatística (IBGE), em 2015 revelam que a produção de soja e arroz na época utilizou mais de 170.000 ha, é válido ressaltar que, a cada ano as empresas expandem suas produções. Teoricamente podemos observar que mais de $1.700 \mathrm{~km}^{2}$ de sua área são utilizadas apenas para produção de grãos, um percentual que ultrapassa $20 \%$ da área total do município (IBGE, 2016).

As empresas entrevistadas mostraram internamente a preocupação mediante a problemática da questão ambiental. Para Donaire (1999), as organizações de modo particular, têm sofrido grandes influências em seu ambiente interno, não obstante à percepção da sociedade geral. Todos os entrevistados responderam positivamente acerca da preocupação que demonstram para com a questão ambiental, e acreditam no crescimento paralelo entre economia e meio ambiente.

Contudo, a preocupação não é suficiente para que aconteça uma mudança no ambiente administrativo, para isso, são necessárias atitudes concretas. A análise revelou que $80 \%$ dos entrevistados já promoveram ações para viabilizar mudanças, e mesmo conscientes da necessidade do equilíbrio os outros $20 \%$ ainda não realizaram nenhum trabalho para atender essa perspectiva.

Percebeu-se que os entrevistados demostram certo alinhamento em suas empresas, rumo à gestão ambiental. Ao analisar a frequência percentual da compreensão das mesmas, conforme cada princípio, temos: a) A questão ambiental como prioridade dentro da organização, em $40 \%$ delas; b) Parte da organização política - 60\%; c) Fundamento para o aperfeiçoamento de políticas e programas sustentáveis - 80\%; d) Formação, treinamento e motivação de recursos humanos - 40\%; e) Avaliação de riscos antes do processo produtivo - 80\%; f) Fontes de recursos que não geram impactos sobre o ambiente - $20 \%$; g) Maneira de informar os clientes formas corretas de manuseio de produtos - 20\%; h) Métodos de consumo de energia e materiais - 60\%; i) Patrocínio e realização de pesquisas sobre impactos ambientais - 20\%; j) Cuidados para evitar e comercializar sem causar graves danos - 60\%; l) Contrata fornecedores sustentáveis - 60\%; m) Controle específico, contra os riscos e emergências de impactos - 60\%; n) transferência de tecnologia e métodos de gestão sustentáveis - 60\%; o) Programas externos com a sociedade e governo que valorizam a conscientização - 20\%; e p) Definição de medidas que acabem com as consequên. cias drásticas - $100 \%$.

Por estes princípios, elaborados por Andrade et al. (2000) e baseado em Kraemer (2004), pode-se compreender que para que as organizações trabalhem com a gestão ambiental devem, inevitavelmente, responder aos princípios básicos e reformular sua cultura organizacional com a revisão de seus paradigmas. Por conseguinte, da análise podemos concluir que, os entrevistados deixam a desejar no que concerne aos impactos ambientais causados; metodologias de tornar inteligível aos clientes sobre a correta forma de manuseio dos produtos; investimentos em projetos e pesquisas socioambientais. Revela-se ainda, que muito pouco tem sido desenvolvido com relação a esses princípios, exceto, na avaliação de riscos e segurança interna.

A necessidade contemporânea exige que as empresas sejam comprometidas na prática efetiva de medidas de planejamento e gestão ambiental em sua política econômica. Quando questionados sobre a existência de um estatuto próprio relacionado ao trabalho com o meio ambiente e seus recursos, $80 \%$ dos produtores não possuem um estatuto de gestão ambiental, apenas $20 \%$ possuem esse documento que delineia a atuação em observação à adequação ambiental. Vale lembrar que, quando as empesas que contratam profissionais habilitados na 
área, estas possuem maior influência de acertos, no que se refere à consciência dos colaboradores, além de formação de colaboradores, treinamento, adequação e conservação dos recursos naturais.

A gestão ambiental é uma abordagem sistêmica em que a preocupação com o meio ambiente está em todos os aspectos do negócio das organizações (Costa et al., 2007). Ainda segundo os autores, as empresas passam a executar e monitorar planos em suas organizações adequando-se às leis. As agências fiscais estão mais preocupadas e treinadas para identificar essa regularização por parte do empresariado com a legislação em vigor. Apesar de não existir o estatuto na maioria das empresas, $70 \%$ delas definem suas responsabilidades com o meio ambiente, inclusive, apresentam programas de conscientização do ambiente interno.

No Estado do Piauí, as reservas legais que deveriam ser de $20 \%$ da área da propriedade, por força da Lei $\mathrm{n}^{\circ}$ $5.178 / 2000$, foi alterada pela Lei $\mathrm{n}^{\mathrm{o}}$ $5.699 / 2007$ e hoje devem ser de $30 \%$ (Piauí, 2007). Desta forma, todas as empresas entrevistadas afirmam possuir essa área de proteção em suas propriedades, inclusive essa reserva não correspondem aos limites de preservação permanente.

Portanto, visto que estas fazendas possuem esse enquadramento na Lei Estadual, com relação às áreas desmatadas, os administradores são conscientes dos danos causados à fauna $\mathrm{e}$ flora da região. Embora, segundo eles a fauna se encontra, em grande parte, ameaçada pela presença dos caçadores locais e pela falta de fiscalização que impeça essa atuação irregular.

Nesse sentido, as áreas desmatadas ainda não sofreram o abandono, sendo que em $100 \%$ das empresas elas foram reutilizadas para o plantio. Já com relação às áreas utilizadas para reflorestamento, $40 \%$ das propriedades entrevistadas já utilizaram essa medida, contudo, para fazer o reflorestamento as empresas têm utilizado o eucalipto, e sabe-se que o mesmo não é típico do cerrado, na maioria das vezes prejudicando o crescimento de árvores nativas da região no entorno.

Apesar de o preço dos produtos ambientalmente corretos, serem mais elevados, as ações sustentáveis por parte das organizações, revela o potencial competitivo e garante o manuseio correto dos insumos naturais, assim, garante a sobrevivência da empresa numa ótica social, ambiental e econômica (Donaire, 1999). Nesse sentido, é importante comentar sobre a atuação das entrevistadas em relação ao manuseio dos intensivos e estimulantes químicos, pois os agrotóxicos são partes fundamentais no processo produtivo agrícola e, considerados verdadeiros inimigos da saúde da natureza e humana.

Os sujeitos pesquisados assumiram a utilização de grandes quantidades de agrotóxicos, sendo que $80 \%$ das empresas reconhecem que os agrotóxicos causam danos diretos ao solo, água, ar, animais e aos trabalhadores que manuseiam os produtos. Os $60 \%$ relativo à resposta outros, referem-se aos consumidores que também são afetados, quando usados em quantidades exageradas. Portanto, ficou entendido que as empresas necessitam utilizar essa grande quantidade de intensivos e, segundo eles, o manuseio correto e adequado não implicaria em danos diretos a nenhuma das alternativas.

Sobre o assunto, Faria et al. (2004) afirmam que o uso indiscriminado de agrotóxicos acarreta muitos problemas, se usado sem respeitar as normas de segurança e sem orientação técnica, podem contaminar o ambiente como um todo. Dessa forma, como a sociedade precisa dessa produção agrícola, e as mesmas necessitam dos agrotóxicos, então, é viável fazer o manuseio discriminado e correto para que o ambiente não seja prejudicado. 
Ainda no intuito de identificar as ações sustentáveis, constatou-se que o percentual de empresas que devolvem as embalagens ao fornecedor é de $60 \%$, os $40 \%$ restantes responderam que fazem a devolução ao órgão de recolhimento da cidade e à uma cooperativa de reciclagem de outro município. As empresas são cientes da importância do manuseio correto com as embalagens, não obstante, as mesmas não são queimadas, jogadas no lixo ou enterradas, e que o principal motivo para que se destinem corretamente as embalagens de agrotóxicos é diminuir o risco para a saúde das pessoas e contaminação do meio ambiente (Alencar et al., 1998).

Depreendeu-se que as empresas têm destinado corretamente as embalagens, visto que, os próprios fornecedores são fundamentais no processo de mobilização quanto à forma de manusear o produto e destino final desses recipientes. É valido citar a importância da ligação entre os entre fornecedores e empresas, para que juntas promovam a sustentabilidade.

Quando questionados sobre os bônus adquiridos com a atenção às questões ambientais, na visão das empresas pesquisadas, um percentual de $100 \%$ percebe o beneficio direto da gestão ambiental para o: a) solo; b) água; c) fauna; d) flora; e) ar; f) empresa; e, g) comunidade. 0 item fornecedor é também identificado como beneficiário, embora, apenas $80 \%$ dos entrevistados possuem essa percepção. Revelou-se que a distância do local onde as empresas estão instaladas, os tornam beneficiários indiretos, mediante o processo.

Essa percepção é muito importante por parte das empresas. Nesta acepção, Kraemer (2004) dispõe que a gestão ambiental facilita o processo de gestão, proporcionando vários benefícios às organizações. Primeiro, elas são motivadas a visualizarem essa melhoria na economia de custos, competitividade e no incremento de receitas à organização. Pois, a gestão voltada para essa preocupação aglomera valores que são fundamentais para que toda a sociedade seja beneficiada com os ganhos recorrentes.

Com relação aos resultados econômicos, detectou-se que $80 \%$ das empresas compreendem a influência da gestão ambiental. 0 mesmo escore é identificado quanto a abertura de novos mercados; redução de perdas e desperdícios; aumento da produção; interação com órgãos do governo e comunidade; e, no destaque competitivo. Nesta mesma perspectiva, $100 \%$ dos entrevistados identificaram ainda a influência direta ao bem-estar social e melhoria da imagem da organização.

Essa percepção aponta o que Sanches (2000) e Tachizawa (2007) discutem sobre a influência de requisitos que promovem a inovação ambiental mostrando que os produtos das empresas verdes geram a rentabilidade e economia de recursos, e não de custos, ou seja, os são ganhos satisfatórios. Quando as empresas se alinham à gestão ambiental, potencializa sua estratégia competitiva, e mesmo com o aumento no preço dos produtos, a sociedade tem optado por técnicas verdes, procurando por produtos e serviços sustentáveis. Essa visão é identificada pela gestão das empresas pesquisadas, visto que são conscientes da importância e benefícios gerados quando executam políticas ambientais.

Mas, para interagir nesse novo modelo de gestão as empresas são desafiadas por alguns fatores, compreendeu-se que a falta de recursos naturais não é um desafio para a implantação do sistema de gestão ambiental nas empresas. A infraestrutura e os recursos humanos são indisponíveis para 30\% dos entrevistados. Outros $40 \%$ responderam que o grande desafio se encontra na falta de incentivos do governo e fiscalização adequada, principalmente para com os caçadores ilegais. $60 \%$ responderam encontrar uma barreira na adequação à legislação rigorosa, bem como, com relação às técnicas viáveis, impedindo que 
empresários atuem ativamente de acordo com medidas ambientais. 60\% dos entrevistados acrescentaram também, como desafios, a readequação a esse novo modelo de gestão, alegando que uma mudança na estrutura do ambiente não acontece no curto prazo.

A respeito desses desafios encontrados pela gestão ambiental das empresas, Jabbour e Santos (2006), relacionam que no século XXI, muitas coisas acontecendo, 0 mundo tem acelerado o ritmo de consumo e aí surgem os vários problemas que desafiam a gerência ambiental. Um dos principais motivos vai de encontro à readaptação aos novos métodos de gestão, mesmo assim, os produtores agrícolas devem reestruturar-se, cientes de que somente essa mudança será capaz de possibilitar o sustento futuro.

No setor interno das empresas do agronegócio, o que tem surgido como um problema para que a mesmas se dediquem ao trabalho da gestão ambiental, não tem sido a inviabilidade do crescimento equilibrado, nem a falta de interesse dos gestores. Entretanto, em $30 \%$ delas não existem profissionais capacitados para que a mesma se enquadre nesse novo modelo de política interna. Para 50\% dos entrevistados existe problema na alta demanda de consumo, pois com o aumento de procura por parte dos consumidores e, alinhados às suas missões de ofertar esses produtos a contento, prioriza-se o atendimento a essa expectativa externa.

Identifica-se ainda, que outro problema diz respeito à falta de novos mercados, isso faz com que $70 \%$ das organizações agrícolas agridam o meio ambiente, por reconhecerem a necessidade de seu trabalho e não visualizarem uma abertura de um novo cenário para que a produção equitativa seja efetivada. 0 governo local deixa de atender a expectativa de $40 \%$ dos entrevistados, que reclamam inclusive da falta de fiscalização para com os agressores locais. E por fim, a infraestrutura se enquadra como um empecilho para que $20 \%$ das mesmas se adequem à politica ambientalmente correta.

Deste modo, Sanches (2000) ratifica que um problema que caracteriza esse processo inovador, diz respeito ao medo de encarar novos paradigmas, pois são necessárias intervenções diretas da alta direção, treinamento e conscientização sobre a importância nesta readequação. Certifica-se então, que as empresas estão conscientes da necessidade de implantação desse novo modelo, mas retirar do papel tem sido complicado, devido à existência de alguns problemas que tem impedido essa postura coerente com a questão dos recursos naturais e sua conservação.

A forte pressão da sociedade no decorrer dos anos, fez com que o governo criasse órgãos para atuarem na fiscalização e cobrança corporativa consciente de suas atuações sustentáveis (Ferraz e Motta, 2002). Na coleta dos dados relativa às multas aplicadas pelo IBAMA, 80\% responderam nunca terem sido multadas, embora os $20 \%$ alegaram ter recebido alguma multa decorrente de um possível erro fiscal na aplicação.

Mediante o exposto, ressalta-se que no ambiente agrícola as empresas carecem refletirem continuamente, na obtenção de melhores resultados socioambientais, favorecendo um ambiente que promova o bem-estar social, ambiental e econômico. Dessa forma, o bom senso instiga toda a sociedade a permanecer com o desejo de mudança, ao invés de procurar os culpados pelos desastres que vem ocorrendo no mundo. É crucial que os impactos de todas as atitudes sejam minimizados, através da adoção de novas posturas, voltadas para a conservação da natureza. Não obstante, as empresas possuem papel estratégico através do planejamento e execução de políticas sustentáveis, haja vista seu papel no seio da sociedade.

Não cabe aqui visualizar a ação em uma posição ambientalista na defesa radical da causa, nem uma visão de 
desenvolvimento que defende o agronegócio como atividade única $\mathrm{e}$ necessária. A ideia é justamente fazer que as duas correntes unam forças para o crescimento equilibrado entre o social, econômico e ambiental. E, esse papel concerne aos governos, empresariado e toda a sociedade.

\section{Considerações finais}

A conscientização é um passo fundamental para a preservação do meio ambiente, pois sem o reconhecimento das pessoas e empresas, não seria possível conter os efeitos decorrentes do uso incorreto dos recursos, e acaba prejudicando toda a sociedade.

A análise permitiu averiguar a presença das empresas e sua contribuição para o desenvolvimento na região sul piauiense, embora a gestão precise compreender e agir de forma ética com os fatores ambientais, para o desenvolvimento da agricultura empresarial. Como consequência dessa relação, as empresas estão totalmente cientes de suas obrigações, principalmente diante de forças externas que lutam freneticamente pela efetivação desse entendimento. Assim, as empresas visualizam aberturas para reformular suas ações, embora, paralelo a esse intuito, encontram problemas externos e internos que são associados à acomodação verificada.

No âmbito dos desafios para o aperfeiçoamento da gestão ambiental constatamos que a readaptação à nova política no setor interno da organização, tem levado as empresas a investirem em motivação, treinamento e capacitação de profissionais, bem como, priorizar a análise de riscos decorrentes de suas ações, para não comprometerem a saúde ambiental com atitudes irresponsáveis.

Deste modo, um passo importante foi analisado, pois as empresas estão esclarecidas e reconhecem que a gestão ambiental pode integrar as políticas institucionais ligadas ao crescimento da produção, embora, somente isso não seja suficiente, é necessária a observância da legislação, e acima de tudo, promover o crescimento com os recursos disponíveis, mas que utilize para isso técnicas viáveis que estejam relacionadas com a tríade ambiental, social e econômica.

A legislação somada à fiscalização por órgãos do governo, as pressões externas dos clientes e fornecedores fazem com que a postura das empresas modernas marche rumo à sustentabilidade, visto que, estas são desafiadas no emprego de atitudes conscientes, para que atendam as pressões que a própria sociedade consumista tem exigido das mesmas.

Enfim, em decorrência dessas pressões e da nova dinâmica das empresas, os custos ambientais estão sendo internalizados pelas organizações, vinculando-se ao ambiente competitivo. Este é um dos benefícios fundamentais encontrado pelos que pretendem atuar no mercado verde, e garantir a melhoria de vida contínua para a sociedade na qual está inserido. Nesta perspectiva, alguns empreendedores ousados buscam estar alinhados à nova gestão e fazem a sua parte contribuindo com a sociedade e com o seu próprio futuro como organização, ao passo que precisa ser investido em melhoria contínua.

0 trabalho limita-se à identificação e validação de medidas adotadas por empresas que são do ramo do agronegócio, localizadas no Sul do estado piauiense. Compreendemos as dificuldades no desenho de estudos que retratem casos com a abordagem de um tema que tem crescido de forma acelerada na academia. Os dados empíricos servem para reforçar a teoria referente às práticas de gestão ambiental, enquanto importante tema a ser estudado, pois corrobora com a validação teórica, bem como, apresenta resultados práticos, servindo de modelo ou embasamento para a atuação de outras empresas.

Desta forma, considera-se que os dados não possuem caráter genérico, 
mas que pode ser estendido a outras empresas do ramo agropecuário, ou até mesmo de outros setores, independente do ramo de atuação. Inclusive, esta ideia poderá ser usada para aprimorar a práticas de gestão ambiental de empresas; destacar os principais desafios e problemas enfrentados junto à adequação ambiental; e, propor ferramentas e mecanismos que viabilizes planejamentos estratégicos a execução de politicas socioambientais.

Portanto, entende-se que no que se refere ao desenvolvimento atual das empresas do agronegócio frente ao desenvolvimento sustentável, será necessário promover uma nova postura prática. Para isso, vários estudos ainda devem ser levantados para melhor avaliar os efeitos e perturbações encontrados no ambiente empresarial, que busca em sua promoção de crescimento utilizar os métodos ambientalmente corretos e socialmente justos.

\section{Conflito de interesses}

Os autores declaram não haver conflito de interesses.

\section{Referências}

Alencar, J. A.; Lima, M. F.; Carvalho, G. A.; Oliveira, C. M. Descarte de embalagens de agrotóxicos. Pesticidas: Revista de Ecotoxicologia e Meio Ambiente, v. 8, p. 9-26, 1988. https://doi.org/10.5380/pes. v8i0.39502

Almeida, F. 0 bom negócio da sustentabilidade. Rio de Janeiro: Nova Fronteira, 2002.

Andrade, R. O. B.; Tachizawa, T.; Carvalho, A. B. Gestão ambiental: enfoque estratégico aplicado ao desenvolvimento sustentável. São Paulo: Pearson Makron Books, 2000.

Barbieri, J. C. Gestão ambiental empresarial: conceitos, modelos e instrumentos. São Paulo: Saraiva, 2004.

Barbieri, J. C. Organizações inovadoras sustentáveis. In: Barbieri; J. C.; Simantob, M. Organizações inovadoras sustentáveis: uma reflexão sobre o futuro das organizações. São Paulo: Atlas, 2007.

Bateman, T. S.; Snell, S. A. Administração: construindo vantagem competitiva. São Paulo: Atlas, 1998.

Bell, S.; Morse, S. Sustainability indicators: measuring the immeasurable? 2. ed. Londres: Earthscan, 2008.

Boff, L. Saber cuidar: ética humana compaixão pela terra. 13. ed. Petrópolis: Vozes, 2007.

Bogdan, R.; Biklen, S. Investigação qualitativa em educação: uma introdução à teoria e aos métodos. Porto: Porto Editora, 1994.

Cavalcanti, C. Desenvolvimento e Natureza: estudo para uma sociedade sustentável. São Paulo: Cortez, 1998.

Cervo, A. L.; Bervian, P. A.; Silva, R. Metodologia científica. 6. ed. São Paulo: Pearson Prentice Hall, 2007.

CMDMA - Comissão Mundial sobre Desenvolvimento e Meio Ambiente. Nosso futuro comum. 2. ed. Rio de Janeiro: Editora da Fundação Getúlio Chagas, 1991.

Copobianco, J.P. Meio ambiente: educação ambiental por decreto. Folha de S. Paulo, 6 abr. 1990.

Costa, A. C. R.; Camelo, G. L. P.; Souza, S. S.; Maia, S. S. A gestão ambiental influenciando o desempenho competitivo das empresas exportadoras. Holos, Ano 23, v. 3, p. 185-194, $2007 . \quad$ https://doi.org/10.15628/holos. 2007.149

Dias, R. Eco-Inovação: caminho para o crescimento sustentável. São Paulo: Atlas, 2014.

Donaire, D. Considerações sobre a influência da variável ambiental na empresa. Revista de Administração de Empresas, v. 34, n. 2, p. 68-77, 1994. http://doi.org/10.1590/ S0034-75901994000200008

Donaire, D. Gestão ambiental na empresa. 2. ed. São Paulo: Atlas, 1999.

Elkington, J.; Burke, T. The green capitalists. London: Victor Gallancz, 1989.

Espinosa, H. R. M. Desenvolvimento e meio ambiente sob nova ótica. Ambiente, v. 7, n. 1, p. 40-44, 1993.

Faria, N. M. X.; Facchini, L. A.; Fassa, A. C. G.; Tomasi, E. Trabalho rural e intoxicações por agrotóxicos. Caderno de Saúde Pública, v. $20, \quad$ n. $5, \quad$ p. $1298-1308,2004$. 
https://doi.org/10.1590/S0102-311X20040 00500024

Ferraz, C.; Motta, R. S. Regulação, mercado ou pressão social? Os determinantes do investimento ambiental na indústria. Rio de Janeiro: IPEA, 2002. (Texto para discussão, 863).

Ferreira, F. J. L C. Gestão ambiental. Teresina: UFPI/CEAD, 2010.

Gil, A.C. Como elaborar projetos de pesquisa. São Paulo: Atlas, 2010.

IBGE - Instituto Brasileiro de Geografia e estatística. 2016. Disponível em: $<$ http://www.ibge.gov.br/home/>. Acesso em: 28 jul. 2017.

Jabbour, C. J. C.; Santos, F. C. A. Evolução da gestão ambiental na empresa: uma taxonomia integrada à gestão da produção e de recursos humanos. Revista Gestão \& Produção, v. 13, n. 3, p. 435-448, 2006. https://doi.org/10.1590/S0104-530X2006 00030000

Kraemer, M.E.P. Gestão ambiental: um enfoque no desenvolvimento sustentável. 2004. Disponível em: <http://www.gestio polis.com/canales3/ger/gesamb.htm>.

Acesso em: 05 mar. 2012.

Lakatos, E. M.; Marconi, M. A. Metodologia científica. São Paulo: Atlas, 2010.

Leff, E. Saber ambiental: sustentabilidade, racionalidade, complexidade, poder. Petrópolis: Vozes, 2001.

Neves, J. L. Pesquisa qualitativa: características, usos e possibilidades. Cadernos de Pesquisas em Administração, v. 1, n. 3, p. 1-5, 1996.

Piauí. Lei no 5.178, de 27 de dezembro de 2000. Dispõe sobre a política florestal do Estado do Piauí e dá outras providências. Disponível em: <https://www.leisdopiaui. com/single-post/2017/02/26/Lei-517800--Pol\%C3\%ADtica-Florestal>. Acesso em: 28 jul. 2017.
Piauí. Lei Ordinária no 5.699, de 26/11/2007. Altera a Lei no 5.178, de 27 de dezembro de 2000, e dá outras providências. Disponível em: <http://legislacao.pi.gov.br/ legislacao/default/detalhe/13386>. Acesso em: 28 jul. 2017.

Porter, M. E.; Kramer, M. R. Strategy e society: the link between competitive advantage and corporate social responsibility. Harvard Business Review, p. 1-15, dez. 2006.

Quezada, R.; Pierre, C. V. Gestão Ambiental Empresarial. 1ㅇ, 2으, 3ำ e 4o módulos. Rio de Janeiro: SEBRAE, UFRJ, 1998.

Sanches, C.S. Gestão ambiental proativa. Revista de Administração de Empresas, v. 40, n. 1, p. 76-87, 2000. https://doi.org/ 10.1590/S0034-75902000000100009

Sachs, I. Estratégias de transição para o século XXI: desenvolvimento e meio ambiente. São Paulo: Nobel, 2002.

Sachs, I. Rumo à Ecossocioeconomia: teoria e prática do desenvolvimento. São Paulo: Cortez, 2007.

Seiffert, M. E. B. ISO 14001 Sistemas de Gestão Ambiental: implantação objetiva e econômica. 3. ed. São Paulo: Atlas, 2007.

Silva, L. H. Gestão ambiental: rumo ao desenvolvimento sustentável. Taubaté: UNITAU, 2003. (Monografia MBA). Disponível em: <http://www.ppga.com.br/ $\mathrm{mba} / 2003 / \mathrm{gpt} /$ silva-luis_henrique_da.pdf $>$. Acesso em: 28 jul. 2017.

Tachizawa, T. Gestão ambiental e responsabilidade social corporativa: estratégias de negócios focadas na realidade brasileira. 4. ed. rev. e ampl. 2. reimp. São Paulo: Atlas, 2007.

Veiga, J. E. Indicadores de sustentabilidade. Estudos avançados, v. 24, n. 68, p. 39-52, 2010. https://doi.org/10.1590/S0103-40142 010000100006

Yin, R. Estudo de caso: planejamento e métodos. 2. ed. Porto Alegre: Bookman. 2010.

Informação da Licença: Este é um artigo Open Access distribuído sob os termos da Licença Creative Commons Attribution, que permite uso irrestrito, distribuição e reprodução em qualquer meio, desde que a obra original seja devidamente citada. 